\title{
ANISTIA DE 1979, JUSTIÇA DE TRANSIÇÃO E COMISSÕES DA VERDADE: APONTAMENTOS E LIMITES
}

\section{AMNESTY, COURT OF TRANSITION AND TRUTH COMMISSIONS: NOTES AND LIMITATIONS}

\author{
Cleidson Carlos Santos Vieira ${ }^{371}$
}

Resumo: 0 objetivo deste artigo é analisar o processo de transição da ditadura civil-militar, assim como as relações estabelecidas pela elite dirigente em utilizar-se desse processo para impor uma democracia representativa frente às atrocidades cometidas pelo regime autoritário. Nesse sentido, pretende-se recorrer ao contexto de distensão e abertura política para compreender as limitações desse processo, tanto nos marcos institucional e jurídico, a exemplo da constituição de 1988, da Lei da Anistia de 1979, quanto nas políticas públicas de "reparação" às vítimas da ditadura, como as leis de reparação às vítimas do Araguaia, das políticas do acesso aos documentos da época, da caravana da anistia e, por fim, da formação da Comissão da Verdade.

Palavra chave: Transição, justiça, democracia.

Summary: The aim of this paper is to analyze the transition of civil-military dictatorship, as well as the relationships established by the ruling elite to utilize this process to impose a representative democracy in the face of atrocities committed by the authoritarian regime. Accordingly, it is intended to refer to the context of political opening and distension; to understand the limitations of this process both in the institutional and legal frameworks such as the constitution of 1988, the Amnesty Law of 1979, as the public policy of "repair" to the victims of the dictatorship, like the laws of reparations to victims of the Araguaia, policies on access to documents of the time, the caravan of amnesty and finally the formation of the truth Commission.

Keyword: Transitional justice, democracy.

\section{INTRODUÇÃO}

A temática da transição tem sido amplamente discutida na historiografia brasileira. Isso porque tem se pensado e avaliado profundamente as posturas e posicionamentos dos setores sobre o verdadeiro caráter da ditadura. Essa mesma historiografia debruçou-se em analisar as medidas de justiça em relação às violações dos Direitos Humanos e também os resquícios do autoritarismo ainda presentes na atual democracia.

${ }^{371}$ Mestrando em História pela Universidade Federal de Alagoas 
Discutir essas questões significa trazer para o presente os aspectos que tentam ser ocultados por medidas de segurança nacional, que ao impedirem o acesso a arquivos beneficiam os torturadores e legitimam determinadas atrocidades ainda existentes em nossa sociedade.

Este artigo partirá de uma visão que compreende o processo de transição como um caminho negociado ao permitir, ainda no tempo presente, os elementos autoritários da ditadura. Com isso, torna-se necessário debruçar-se sobre os acordos estabelecidos no processo de transição, bem como na construção de uma memória coletiva que tem subsidiado a formação de uma "história oficial" voltada para os vencedores.

Partindo dessa perspectiva, Walter Benjamin, ao escrever sobre o conceito de história, nos traz elementos teóricos importantes que se relacionam à temática abordada, na medida em que enfatiza a escrita da história enquanto instrumento de comparação, e aproximação do passado ao presente, não para reconstruir o passado exatamente como ele foi, mas sim para reconhecê-lo enquanto um instrumento indispensável ao presente de luta. O autor também aborda o conceito de apropriação no sentido de tomar para si, fazer uso, isso não significa que o papel dele é se apropriar de uma época, mas sim transformá-la em reminiscência. Assim, o próprio passado e seus sentidos só ganham relevância na relação originária com os problemas liberados pelo presente (BENJAMIN, 1996, p. 224).

Certamente, o direcionamento dado pela burguesia na transição possibilitou a construção da história para os interesses dos vencedores, pois junto a essa memória somam-se os aspectos do ocultamento da verdade e a injustiça. Neste sentido, as violências cometidas pelos agentes do Estado deveriam ser esquecidas a fim de que não houvesse comprometimento das suas instituições, usando 0 argumento da unidade nacional.

O objetivo desse artigo, portanto, é trazer uma reflexão sobre o processo de transição no Brasil apontando as principais limitações que recaem sobre as vítimas do regime, e pela parcela mais pobre da população.

\section{CONTEXTO HISTÓRICO E APONTAMENTOS DA TRANSIÇÃO NO BRASIL}

A segunda metade do século XX foi marcada pela intervenção militar em diversos países da América Latina. Estas intervenções não só buscavam eliminar as suspeitas dos chamados "subversivos", como também construíram estruturas econômicas e políticas que pautavam a modernização e o desenvolvimento 
de suas sociedades nos marcos da doutrina de segurança nacional. Este processo se deu através da implantação de um capitalismo que seguia o modelo norte americano de desenvolvimento.

Neste caso, a ditadura foi indispensável para a burguesia manter seus interesses e privilégios econômicos e políticos. Segundo João Quartim de Moraes (2014, p. 63), a burguesia não teria nenhum compromisso de princípio com a democracia. Porém ela cumpre um papel extremamente importante, pois impõe uma ideologia que separa os aspectos políticos e econômicos nas relações capitalistas.

A democracia é uma categoria política, não é necessário apenas constatar (e descrever) o uso ideológico que faz dela a burguesia. É necessário, sobretudo, determinar o conteúdo politico da contradição entre burguesia e democracia. Mais precisamente, sabemos que essa contradição pode se exprimir sob a forma de uma separação entre as duas categorias (a burguesia nega a democracia, tornando-se fascista ou simplesmente autocrática). Pode também se exprimir por sua síntese (a democracia burguesa). Mas o que decide entre a síntese e a separação entre democracia e burguesia? A luta de classes, evidentemente. (MORAES, 2014, p. 65).

O historiador René Armand Dreifuss promoveu uma exaustiva pesquisa nos arquivos do Instituto de Pesquisa e Estudos Sociais (IPES) e o Instituto Brasileiro de Ação Democrática (IBAD) e constatou que ambos os organismos foram os principais instrumentos desse processo, articulando uma ampla rede de conspiração em todo o país e formulando um projeto de poder que se implantou no Estado brasileiro no pós-golpe.

O resultado dessa pesquisa permitiu a publicação do livro 1964, a conquista do estado, o qual apresentou elementos indispensáveis que destacam a participação dos civis, ligados ao setor empresarial, na tomada do estado e na instauração da ditadura. O que comprova a participação da burguesia no golpe que depôs o presidente João Goulart e toda sua base aliada. (DREIFUSS, 1981,p.145).

Aqueles que se colocavam contrários a esse projeto político econômico eram considerados inimigos da pátria e, portanto, seriam perseguidos e eliminados da sociedade. A repressão ao movimento estudantil, proibição de greves, instauração da censura, criação de serviços nacionais de segurança, a intervenção aos sindicatos, e cassação de mandatos foram as principais medidas tomadas pelos militares em seus respectivos países. As torturas, os sequestros, os desaparecimentos, genocídios e banimentos se converteram na realidade cotidiana que envolveu milhares de pessoas, em um contexto controlado pelo medo e pelo terror.

A transição desse período para a atual democracia foi caracterizada por uma crise desenvolvimentista que aprofundava as contradições existentes no sistema capitalista, tendo seu ápice com a queda do preço do petróleo em 1973. Essa crise, segundo David Maciel (2014,_p. 175) definiu o eixo político pós-ditadura e 
influenciou para que o processo de transição no Brasil tivesse um caráter "lento gradual e seguro". Para 0 autor:

O processo de democratização se desenrolou de modo lento, gradual e o mais seguro possível para as classes dominante, garantindo a superação da institucionalidade política autoritária por uma institucionalidade democrática por meio de um processo de reforma da autocracia burguesa, porém, ao custo de impossibilitar a retomada do desenvolvimentismo e de uma perspectiva de desenvolvimento capitalista menos dependente e mais distributivo. Mais do que isto, a combinação entre crise do desenvolvimentismo e transição política desencadeou uma crise de hegemonia que tornou a transição um processo lento e difícil, apesar da não ocorrência de retrocessos, pois tornou os distintos agentes sociais incapazes de solucionar a crise rapidamente em seu favor, tornando a solução definitiva, para um lado ou para outro, crescentemente custosa no sentido de exigir a ruptura com a própria transição, seja pelo retrocesso, seja por sua aceleração democrática. (MACIEL, 2014, p. 175,176).

A concretização dessa análise se dá na politica de "distensão" do Governo Geisel, pois fazia uma ponte entre os mecanismos de repressão e o controle por meio de mudanças nas instituições de poder, a exemplo da revogação dos Atos Institucionais e reformas da Lei de Segurança Nacional.

Esta era uma forma de controle das Forças Armadas sobre o processo de abertura política para impedir que a oposição de esquerda se tornasse maioria ao longo do processo. Com o assassinato do jornalista Vladmir Herzog em outubro de 1975, e do operário metalúrgico Manoel Fiel Filho, em janeiro de 1976, vários familiares abriram processos judiciais incriminando o Estado pelas mortes.

Havia pressões externas condicionadas tanto pela reestruturação da economia global quanto pela ascensão de Jimmy Carter à presidência dos EUA (SILVA, 2007, p.246). O Presidente norte-americano criticava o regime do bipartidarismo, a violação dos direitos humanos presente nas denúncias de torturas e defendia a liberdade de expressão, de organização.

Essas pressões, segundo David Maciel (2014,p. 274) significaram uma crise de hegemonia que na sua aparência apresentava-se apenas como algo conjuntural, porém em sua profundidade expressava a desarticulação da burguesia tendo a transição "lenta, gradual e segura" um momento de recomposição de uma unidade com o intuito de constituir um novo momento histórico caracterizado pelo neoliberalismo.

Nesse sentido, abriu-se um cenário em que se constituísse uma democracia representativa, limitada, onde os seus dirigentes anularam quaisquer atuações que comprometessem as estruturas do Estado. Florestan Fernandes analisa essas questões argumentando que:

Os estratos sociais burgueses que têm peso e voz na sociedade civil promovem esse enlace trágico, pelo qual logram manter, pela via política, as bases sociais de uma dominação de classe tão intolerante quão intolerável e de uma democracia restrita artificial, que se atrita com a própria expansão interna do capitalismo e com os requisitos históricos de qualquer modalidade de 'paz social' com a classe operária (FERNANDES, 1982, p. 145). 
Ainda Segundo Florestan Fernandes (1982, p. 105), a "transição lenta, gradual e segura" permitiu uma conciliação entre burguesia nacional e capital externo após a crise do Milagre Econômico. A institucionalidade democrática sob o Estado capitalista demonstrou flexibilidade dos grupos autoritários diante das contradições provocadas pela crise do modelo econômico desenvolvimentista.

Os atos de contestação e protestos foram se multiplicando a partir da década de 70, 0 que contribuiu para a crise do regime autoritário. Por um lado, a luta por Direitos Humanos, que se relacionava ao fim das torturas, à retomada do processo democrático e à bandeira da Anistia aos presos, cassados, banidos, exilados e perseguidos políticos, que envolvia amplos setores da sociedade organizada destacando-se o Movimento Feminino pela Anistia, criado em 1975, e o Comitê Brasileiro pela Anistia (CBA), criado em 1978, no Rio de Janeiro. "Anistia Ampla, Geral e Irrestrita" seria a palavra de ordem dessas organizações que, aliados à Igreja Católica, à Ordem dos Advogados do Brasil (OAB) e à Associação Brasileira de Imprensa (ABI), adquiriram repercussão internacional.

Por outro lado, ocorreram agitações políticas de luta contra a retirada de direitos, que envolviam trabalhadores e movimentos sociais. Um exemplo foi a greve dos metalúrgicos do ABC paulista em 1978, possibilitando que outros setores também paralisassem suas atividades. Segundo Marco Aurélio Santana (2014, p. 189), essas agitações trouxeram um rompimento com "os limites estreitos estabelecidos pela lei antigreve, com o 'arrocho salarial' e o silêncio geral ao qual havia sido forçada a classe trabalhadora".

A greve do ABC permitiu a intensificação de manifestações a outras categorias nos anos de $1979 \mathrm{e}$ 1980. Como consequência surge em 1980 o Partido dos Trabalhadores (PT), o Movimento dos Trabalhadores sem Terra (MST) e a Central Única dos Trabalhadores (CUT) em 1983. Esses setores expressavam o que havia de mais combativo na época.

Cabe ainda apontar que, no ano de 1979 com as reformas do governo e o fim do bipartidarismo, a burguesia se organizou em tono de 4 partidos: o PDS (Partido Democrático-social) - em sua maioria originário do ARENA, o PP (Partido Popular) - os moderados do MDB e aqueles que atuavam no interior do MDB, porém eram orgânicos ao PCB, PC do B e MR-8, o PMDB (Partido do Movimento Democrático Brasileiro), o PTB (Partido Trabalhista Brasileiro) - os setores reacionários do antigo trabalhismo. (MACIEL, 2014, p. 283).

A campanha das "Diretas Já" também expressou um ponto importante nesse processo e resultou na articulação desses partidos para direcionar as mobilizações ao plano da institucionalidade. 0 principal objetivo dessa campanha era o reestabelecimento do Estado democrático de direito tendo a emenda Dante 
de Oliveira ${ }^{372} 0$ ponto central às mobilizações. Para isso foi criada uma aliança democrática que envolvia todos os setores de oposição ao regime. Vanderlei Elias Nery (2014, p.259) aponta que o processo que pôs o fim da ditadura trouxe um conceito de "democracia enquanto um valor em si", este por sua vez, possibilitou que a oposição burguesa organizada principalmente no PMDB e no PDT, direcionasse a campanha para que as pautas dos setores combativos da sociedade não fossem atendidas. Segundo 0 autor, esse conceito:

Contribuiu para a definição dos rumos ideológicos da campanha "Diretas Já", que por um lado, contou com extraordinária adesão operária e popular; e, por outro, teve direção politica burguesa tão eficaz que sequer a bandeira da greve geral foi agitada, exceto - e por pouco tempo - por um pequeno e combativo agrupamento politico que ajudara a criar o PT. (NERY, 2014,p.259,260).

Tais rumos permitiram ainda que a oposição burguesa utilizasse da campanha para negociar com os governos militares o processo de sucessão do regime, o que também permitiu uma "reforma da autocracia burguesa, vislumbrado a partir da chamada distensão pelos militares, no momento em que perderam a capacidade de dirigir politicamente o bloco no poder" (MACIEL, 2014, p. 269).Na campanha das "Diretas já", assim como em todo o processo de transição, a oposição burguesa buscou canalizar as manifestações para o jogo político institucional ao âmbito parlamentar. Como resultado dessa negociação, a eleição de 1985 se realizou de forma indireta, onde o colégio eleitoral decidiu o nome de Tancredo Neves a presidente pelo PP (Partido Popular) e o vice, José Sarney do PDS. (NERY, 2014, p. 260). Porém Tancredo Neves morreu antes de tomar a posse e o seu vice assume, num mandato que durou cinco anos.

A condução do processo de transição negociada trouxe ainda a instauração de um regime democrático com a presença forte dos militares, assim como dos políticos que apoiaram a ditadura. Basta observar que este processo que desencadeou a formulação da nova constituição para o Brasil foi convocado com uma forte influência militar. Segundo Jorge Zaverucha (2010, p. 45), se iniciou por meio de uma comissão fechada e sigilosa, pois evitaria uma pressão da opinião pública, levada ao plenário no Congresso para depois ser votadas pelos parlamentares.

A Constituição Federal, por sua vez, consolidava as suas instituições, defendendo os interesses da burguesia e da propriedade privada. Em detrimento disso, criaram-se mecanismos de repressão que mantiveram em voga a violação dos Direitos Humanos para com as comunidades pobres. Esses

\footnotetext{
${ }^{372}$ A lei apontava eleições diretas para o ano de 1985 sendo rejeitada pelo Congresso nacional. Rejeição da Emenda Dante de Oliveira pela Câmara completa 30 anos. Correio Brasiliense. Acesso: $<$ <ttp://www.correiobraziliense.com.br/app/noticia/politica/2014/04/25/interna_politica,424651/rejeicao-da-emenda-dante-deoliveira-pela-camara-completa-30-anos.shtml > em 14 de Setembro de 2014.
} 
mecanismos se caracterizam pela militarização da segurança pública evidenciada na ideia de que "o bloco civil-militar de 1964 não se desfez com o processo de transição" (ARANTES, 2010, p.216).

A chamada "Constituição Cidadã" manteve muitos aspectos de prerrogativas militares que não são democráticas. Por mais que ela tenha descentralizado os três poderes, e estipulado alguns benefícios semelhantes a de países em que possuem um processo democrático mais avançado, ela manteve em parte de seu texto, algumas cláusulas que dão poderes às Forças Armadas e à segurança pública em geral.

Segundo Jorge Zaverucha (2010,p.46), a Constituição "manteve o controle parcial do exército sobre as PMs ( Polícia Militar), alegando que o governo necessitaria de todas as suas forças para controlar contestadores da ordem social". Como resultado as estruturas organizativas das PMs, que seguem 0 modelo dos batalhões das Forças Armadas, são consideradas forças auxiliares do exército. (ZAVERUCHA, 2010, p. 57). Isso significa que as forças armadas têm o direito de intervir na defesa do país contra ameaças e isso inclui as manifestações populares que são reprimidas quando questionam a lógica de dominação capitalista. Além disso, manteve-se também em funcionamento o SNI (Serviço Nacional de Informação), que em 1999 foi substituído pela Abin (Agência Brasileira de Inteligência) e que é responsável por investigar as informações para a garantia da ordem nacional.

As negociações ocorridas ao longo da transição e no processo de elaboração do texto da Constituição também tiveram implicações negativas para os setores combativos da sociedade na época. As reivindicações dos trabalhadores para a elaboração do texto se pautavam pela necessidade de autonomia dos sindicatos ao Estado, ao fim da Lei de Segurança Nacional, ao direito à greve, e à reforma agrária (NERY, 2014, p. 266). Evidentemente que essas reivindicações questionavam os acordos unilaterais estabelecidos entre os setores da burguesia que direcionaram a abertura do regime.

Todos esses elementos impulsionam a reflexão de que a transição brasileira, da maneira que foi direcionada - unilateral, "lenta, gradual e segura", impediu que as reinvindicações das classes populares pudessem intervir no processo para destruir a estrutura militarizada e repressora do aparelho do Estado brasileiro.

Nesse sentido a democracia brasileira que se sustentou no período pós-ditadura, com a retomada do Estado nas mãos dos civis, ocultou por muito tempo as atrocidades que foram cometidas além de não priorizar a justiça e reparação às vitimas. Quando Paulo Eduardo Arantes (2010, p.177) ousa questionar esse período com a pergunta "o que resta da ditadura?" o seu objetivo é analisar os acordos estabelecidos no processo de transição para responder que resta "tudo, menos à ditadura". 
A transição pactuada permitiu ainda uma perpetuação de uma lógica que reconstituiu após o golpe de 1964 uma nova situação estruturada sob a égide do capitalismo em sua nova fase. Cabe, a partir de então, compreender a maneira na qual o Estado democrático brasileiro, com todas as limitações e a forte influência dos militares, tem se comprometido com o processo de reparação das vítimas e a justiça de transição no Brasil.

\section{A JUSTIÇA DE TRANSIÇÃO SOB O ENFOQUE DA LEI DA ANISTIA}

A Lei da Anistia, promulgada no Brasil em agosto de 1979, representou o projeto político conservador de esquecimento, apaziguamento e o perdão do Estado, tendo como elemento fundamental a conciliação imposta por setores dominantes da sociedade civil, capazes, inclusive, de influenciar no processo político em defesa da amnésia. Esta lei permitiu ainda que, por meio da interpretação dos chamados "crimes conexos", fossem beneficiados os militares, torturadores, financiadores das torturas, e o próprio Estado que dirigiu tais atos.

O ano de 1979 foi de muitas expectativas tanto para os movimentos que defendiam a anistia quanto para o parlamento brasileiro. O presidente Figueiredo definiu como agenda política para o primeiro semestre deste mesmo ano, a Anistia. O principal articulador do projeto foi o Ministro da Justiça Petrônio Portella, que, segundo o Jornal da Cidade ${ }^{373}$, também foi o principal responsável por estabelecer as discussões com os diversos setores da sociedade civil.

No dia 27 de junho de 1979, o Presidente Figueiredo assinou o Projeto de Lei que confirmou o seu caráter parcial e restrito. Na mensagem presidencial $n^{0} 59$ analisada na $134^{\circ}$ Sessão conjunta do Congresso Nacional, ocorrida um dia após a assinatura do projeto, o presidente evidenciou o significado da lei para aquela conjuntura:

A anistia é um ato unilateral de poder, mas pressupõe, para cumprir sua destinação política, haja, na divergência que não se desfaz antes se reafirma pela liberdade, 0 desarmamento dos pela convicção da indispensabilidade da coexistência democrática (...) o Projeto, examinado em cortejo com os antecedentes históricos, ganha em dimensão, ao atingir extensa área com pleno esquecimento. (MENSAGEM N 59, DE 1979 CN, 1982, p. 21, 22).

$\overline{373}$ O Projeto de Anistia. Jornal da Cidade. Aracaju (SE) 23/03/1979. p, 02. Ano VIII. № 1952. 
Em seu discurso, Figueiredo reforçava a sua imagem de governante que buscava a paz nacional por meio de uma conciliação imposta, trazendo consigo a política do esquecimento que não levava em consideração a justiça e reparação às vítimas. Desse modo, o governo estendia aos opositores a licença do perdão. Esse aspecto merece um, destaque na discussão, pois permitiu a auto-anistia aos agentes responsáveis pelas atrocidades cometidas ao longo da ditadura. 0 Art. $1^{0}, \S 1^{\circ}$ da Lei abre brecha para essa interpretação:

Art. $1^{0}$ É concedida anistia a todos quantos, no período compreendido entre 02 de setembro de 1961 e 15 de agosto de 1979, cometeram crimes políticos ou conexo com estes (...) § $1^{0}$ Consideram-se conexos, para efeito deste artigo, os crimes de qualquer natureza relacionados com crimes políticos ou praticados por motivação política. ${ }^{374}$

Ao se "auto-anistiar", os membros do Estado assinaram um atestado que acabava perpetuando a impunidade e a injustiça. Ao propor a revisão deste artigo na lei, questiona-se o papel que esse mesmo Estado cumpre para a justiça balizada na memória coletiva. Tratar a anistia numa perspectiva de reminiscência significa repensarmos a memória nacional, sendo ela "também um instrumento e um objeto de poder" (LE GOFF, 2003, p. 470), pois ela representou a limitação do processo de transição ${ }^{375}$ e a afirmação de uma ideologia que hegemonizava e hegemoniza as concepções de quem está no poder.

É bastante recorrente, mesmo depois de quase trinta anos da abertura política, haver declarações e manifestações na defesa de intervenções militares no Brasil. Na sessão que debateu os 50 anos do golpe no Congresso Nacional, figuras como o Deputado Federal Jair Bolsonaro (PP/RJ) parabenizaram a ação das forças armadas naquela época, ressaltando que "se não fosse por eles, o Brasil teria virado Cuba ${ }^{376 . " ~ A t u a l m e n t e, ~ o ~ r e f e r i d o ~ D e p u t a d o ~ e ́ ~ o ~ p r i n c i p a l ~ p o r t a-v o z ~ d e s t a ~ p e r s p e c t i v a ~ n o ~ C o n g r e s s o ~ N a c i o n a l ~}$ Ao mesmo tempo, não é de se admirar que ainda existam publicações como a do editorial da Folha de São Paulo fazendo eco às repressões existentes no Brasil entre 1964 a 1985. O editorial utilizou o termo "ditabranda" 377 para fazer uma colocação irrefletida de como o Brasil foi pouco violento comparado a outros países que foram vítimas das ditaduras civis-militares no Cone-Sul. Ora, diferentemente do que aconteceu em outros países do Cone-Sul, o Brasil é o único país sul-americano onde os torturadores

\footnotetext{
${ }^{374}$ BRASIL. Lei $n^{0} 6.683$, de 28 de agosto de 1979. Disponível em < http://www.planalto.gov.br/ccivil_03/leis/l6683.htm >. Acesso em 08 de dezembro de 2011.

375 Por conta da auto anistia, vários processos de reparação as vítimas permanecem inacabados, na medida em que os atos de violações de direitos humanos não podem ser julgados pois os autores de tais crimes foram anistiados.

${ }^{376}$ Manifestações pró-golpe levam a fim de sessão da Câmara sobre ditadura. Rede Brasil Atual. Disponível em: < http://www.redebrasilatual.com.br/cidadania/2014/04/manifestantes-pro-golpe-tumultuam-sessao-da-camara-sobre-ditadura6533.html > Acesso em: 17 de Abril de 2014.

${ }^{377}$ Limites a Cháves. Folha de São Paulo: <http://www1.folha.u-ol.com.br/fsp/opiniao/fz1702200901.htm > Acesso em: 17 de Abril de 2014.
} 
nunca foram julgados pela justiça, onde ainda vivemos com o ocultamento de cadáveres dos que foram assassinados pelas forças armadas.

O Superior Tribunal Federal (STF) brasileiro tem cumprido um papel retrógrado para a justiça de transição. Observa-se que este organismo se transformou no principal instrumento de gestão da lógica do arbítrio, ao considerar como completamente anistiadas as duas partes, argumentando sobre a necessidade de se manter a paz com a Lei da Anistia.

O Conselho Federal da OAB, na representação de Fábio Konder Comparato, entrou em 2008 com uma Ação de Descumprimento de Preceito Fundamental - ADPF, acerca da Lei da anistia de 1979. 0 julgamento ocorreu em 2010 e os ministros do STF decidiram pela impunidade aos torturadores.

Eros Roberto Grau, relator do julgamento, defendeu que a lei da anistia seria um acordo do governo com a sociedade civil:

\begin{abstract}
Relevantíssima questão submetida ao Supremo Tribunal Federal, entretanto, não comporta exame dissociado do contexto histórico em que editada a norma objeto da arguição, absolutamente decisivo para a sua adequada interpretação e para o juízo definitivo acerca das alegações deduzidas pela Ordem, como, aliás, já destacado em outros pronunciamentos trazidos aos autos. A anistia, no Brasil, todos sabemos, resultou de um longo debate nacional, com a participação de diversos setores da sociedade civil, a fim de viabilizar a transição entre 0 regime autoritário militar e o regime democrático atual. A sociedade civil brasileira, para além de uma singela participação neste processo, articulou- se e marcou na história do país uma luta pela democracia e pela transição pacífica e harmônica, capaz de evitar maiores conflitos. (ARGUIÇÃO DE DESCUMPRIMENTO DE PRECEITO FUNDAMENTAL n 153, 2010, p.07).
\end{abstract}

Se formos analisar o processo que culminou na anistia de 1979, podemos observar que o acordo estabelecido foi entre o governo e os setores conservadores, que tinham como anseio estabelecer uma transição que fosse "lenta gradual e segura". O voto do relator legitimou essa versão equivocada de acordos com a sociedade civil, na medida em que transformou isso em acontecimento histórico. $E$, de forma retórica, o ministro afirmou que a ação equivaleria a negar historicamente a campanha da anistia.

Safatle (2010, p. 242) chama a atenção para as reações de setores do STF a respeito da modificação da interpretação do Artigo $1^{0}$ da Lei da anistia em que se lê: "executam-se dos benefícios da anistia os que foram condenados pela prática de crimes de terrorismo, assalto sequestro e atentado pessoal." Ora, nenhum membro do regime militar deixou de se beneficiar pela Lei da Anistia por ter cometido sequestros e atentado pessoal.

O ex-presidente do STF, Gilmar Mendes, também chegou a dar uma declaração que justificava as ações dos militares e caso eles fossem julgados por tortura, sequestro, atentado pessoal e assassinato e ocultamento de cadáveres, então os antigos membros da luta armada deveriam ter o mesmo destino: 
Não é razoável introduzir, no campo da análise política e no campo das definições jurídicas, compreensões morais acerca da natureza justificadora da violência. Não é possível conferir a ilicitude criminal a alguns atos e, ao mesmo tempo, reconhecer que outros de igual repercussão possuem natureza distinta e podem ser justificados em razão do objetivo político ideológico que os geraram. ${ }^{378}$

Além de articularem a impunidade por meio da auto anistia, os agentes da repressão tentaram ocultar da história a importância da luta dos militantes que ocorria àquela época. Impuseram aquilo que Vladmir Safatle (2010,p.238) chamou de "eliminação simbólica". Para o autor, a base de todo totalitarismo se fundamenta em tornar inomináveis aqueles que se opõem a esse estado:

No cerne de todo totalitarismo, haverá sempre a operação sistemática de retirar o nome daquele que a mim se opõe, de transformá-lo em um inominável cuja voz, cuja demanda encarnada em sua voz não será mais objeto de referência alguma. Este inominável pode, inclusive, receber, não um nome, mas uma espécie de "designação impronunciável" que visa isolá-lo em um isolamento sem retorno. "subversivo", "terrorista". (SAFATLE, 2010, p. 238).

Vladmir Safatle analisa, ainda, as justificativas utilizadas pela ala conservadora de que é preciso manter a "estabilidade democrática a qualquer custo". Segundo o autor, a nossa democracia não é estável e muito menos tem projeção para o aperfeiçoamento. O que acontece é a "desagregação normativa com suspensão de dispositivos legais devido a interferência de interesses econômicos do estado" (SAFATLE, 2010,p. 250).

Mesmo que o STF tenha negado a revisão da Lei da Anistia em 2010, as pressões realizadas pela Ordem dos Advogados do Brasil (OAB), familiares de desaparecidos políticos e grupos que lutam por direitos humanos, contribuíram para que a Comissão de Direitos Humanos do Senado aprovasse no primeiro semestre de 2014 a revisão da Lei da Anistia de $1979^{379}$. Observa-se também que 0 debate da revisão tem conquistado a população de modo geral.

No dia que marcou os 50 anos do golpe de 64, o Datafolha publicou uma pesquisa que apontou que 46\% dos entrevistados são a favor da revisão da Lei de Anistia, e os mesmos 46\% são também favoráveis à punição dos militares pelos crimes cometidos na época. ${ }^{380}$ Essa pesquisa comprovou que, ao contrário do

378 Leia 0 voto de Gilmar Mendes sobre a Lei de Anistia. Portal consultor jurídico. Disponível em: < http://www.conjur.com.br/2010-ago-08/leia-voto-ministro-gilmar-mendes-lei-anistia > Acesso em: 20 de Abril de 2014.

379 Comissão do Senado aprova revisão da Lei da Anistia. Folha de São Paulo. Disponível em: < http://www1.folha.uol.com.br/poder/2014/04/1438111-comissao-do-senado-aprova-revisao-da-lei-da-anistia.shtml > Acesso em: 17 de Abril de 2014.

${ }^{380}$ Maior parte da população quer anular a Lei da Anistia, aponta Datafolha. Folha de São Paulo. Disponível em : < http://www1.folha.uol.com.br/poder/2014/03/1433374-maior-parte-da-populacao-quer-anular-lei-da-anistia-aponta-

datafolha.shtml > Acesso em: 17 de abril de 2014. 
que disse 0 ministro em seus argumentos, o pacto existente no processo de transição brasileiro representou um jogo político da classe dominante distanciando-se dos interesses dos que lutavam contra a lógica do arbítrio.

Podemos com isso afirmar que o "estado de emergência" se materializa nos dias de hoje travestido de democracia, e isto é "vendido como a melhor arma na guerra contra o terror" sem saber que "é ela mesma um produto do terror". (ARANTES, 2010, p.220). Por mais que não tenhamos a institucionalização da repressão como nos anos de ditadura, o estado de emergência econômico permanece latente, principalmente em momentos de crises financeiras, onde seus riscos recaem sobre a parcela vulnerável da população.

A Lei da Anistia foi aprovada, a partir de um projeto do Poder Executivo, em 1979, durante 0 governo do General Figueiredo, e foi considerada constitucional pelo Supremo Tribunal Federal em 2010. Além de não ter sido criada uma comissão da verdade logo quando a ditadura acabou, os governos de Fernando Henrique Cardoso e Luís Inácio Lula da Silva editaram decretos que estenderam indefinidamente o sigilo de documentos oficiais. No caso do Brasil, a justiça de transição manifestou-se apenas no aspecto de indenizações, a partir das leis 9.140/1995 e 10.559/2002, e as Forças Armadas nunca expressaram arrependimento a respeito do período ditatorial. Sem contar que, pelo fato de não ter havido um tribunal contra a ditadura, a justiça nunca rechaçou as práticas típicas dos articuladores do regime autoritário.

Sendo assim, a discussão sobre a política de reparação tem se esbarrado na própria condição estabelecida ao processo de transição brasileira. Fazendo uma análise detalhada podemos observar que a reparação estabelecida desde o final da ditadura não traçou uma perspectiva justa, de recuperação dos restos mortais dos militantes assassinados e de punição aos responsáveis pelos crimes cometidos.

É importante analisarmos que seria necessário o reconhecimento por parte do Estado de que os crimes ocorridos no período da Ditadura foram de sua responsabilidade, bem como de seus agentes. Porém isso só veio se concretizar 10 anos depois do fim da ditadura.

Janaina de Almeida Teles (2010, p. 254) argumenta que, desde a década de 70, dezenas de familiares de desaparecidos políticos têm encaminhado ações à justiça brasileira com 0 objetivo de denunciar 0 Estado pelos crimes cometidos ao longo da ditadura. Porém, segundo a autora, a justiça tem se apresentado insuficiente pois tem encaminhado os processos de maneira muito lenta.

Mesmo com essas dificuldades, muitas das vítimas e familiares de desaparecidos e mortos durante a ditadura civil-militar permaneceram empenhadas na luta por seus direitos socioeconômicos, civis e políticos, pressionando, dessa forma, o Estado brasileiro a promulgar a Lei 9.140 de 1995, que reconhece 
como mortas as pessoas desaparecidas em razão do seu envolvimento com atividades políticas. Esta lei formalizou o reconhecimento e a responsabilidade do Estado pelas violações e atrocidades cometidas durante a ditadura civil-militar, estabelecendo o direito dos familiares dos desaparecidos de requerer atestados de óbito e indenizações. Porém, "essa lei impôs às vítimas o ônus da prova", Janaina de Almeida Teles analisa que:

Não foi possível testemunhar em juízo os responsáveis por crimes tão violentos como as torturas e o desaparecimento forçado. As leis e os decretos que continuam impedindo amplo acesso às informações públicas tornam ainda mais candentes e relevantes a necessidade de se ouvir os testemunhos de sobreviventes da violência do estado ditatorial. (TELES, 2010, p.254).

Ora, naquele momento, nem o Estado muito menos as Forças Armadas se interessaram em investigar tais crimes. As Cortes Interamericanas dizem que, em caso de violação dos direitos humanos, 0 Estado tem a obrigação de investigar e punir os responsáveis. No Brasil, em nome de uma reconciliação forçada, conforme o que significou a Lei da Anistia, essa obrigação fora deixada de lado. (ARANTES,2010, p.211).

Outro elemento a ser levado em conta é que por mais que o Estado reconheça as ações de violação dos direitos humanos, as indenizações pagas representam uma parcela pequena das obrigações para com os familiares dos mortos e desaparecidos. No início de 1982, 22 familiares de desaparecidos da Guerrilha do Araguaia lançaram uma ação comunitária para solicitar a indicação das sepulturas, visando à localização dos restos mortais desses desaparecidos, além de um relatório do Ministério do Exército sobre a operação do Araguaia. Segundo Janaina de Almeida Teles (2010.p.284), somente em 2003, a justiça considerou procedente o pedido dos familiares, porém o governo se contrapôs intervindo com o argumento de que a decisão da justiça estava além da petição inicial solicitada pelos familiares.

Dessa forma, o governo criou uma Comissão Interministerial, por meio do Decreto nº 4.850 de 2 de outubro de 2003, que tinha como objetivo obter informações sobre os desaparecidos e localizar os restos mortais daqueles que lutaram na Guerrilha do Araguaia.

Art. 1ำ Fica constituída Comissão Interministerial, com a finalidade de obter informações que levem à localização dos restos mortais de participantes da Guerrilha do Araguaia, para que se proceda à sua identificação, traslado e sepultamento, bem como à lavratura das respectivas certidões de óbito. ${ }^{381}$

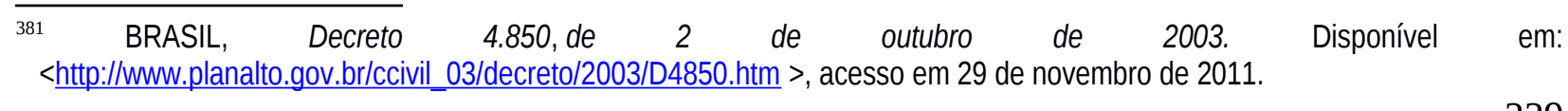


Em 2009, o ministro da Justiça, Nelson Jobim, junto com as forças armadas e a Comissão Interministerial iniciaram o processo de averiguação e localização dos corpos por meio de um grupo de trabalho. Os familiares participariam desse grupo apenas como observadores ativos. Como é possível instituir uma comissão, responsável por investigar os crimes cometidos, sem a participação dos familiares? Em resposta a essa medida do governo, esses familiares escreveram uma carta ao Governo Federal expressando a sua indignação perante a medida:

Que somente agora a ação ora orquestrada pelo Governo Federal responde à sentença judicial da ação interposta pelos familiares de desaparecidos da Guerrilha do Araguaia, já pronunciada há mais de seis anos e transitada e julgada em dezembro de 2007 e 0 faz de maneira inepta e inaceitável; que o Exército, que ora coordena as buscas, levou anos para reconhecer oficialmente a existência da Guerrilha do Araguaia e a participação de seus integrantes nos combates, sem nunca ter assumido as prisões, torturas, assassinatos e desaparecimentos. Que 0 Exército e muitas das instituições vinculadas à União sempre afirmaram que a guerrilha não existiu e negam até hoje a existência de arquivos, sem ter a decência e qualquer sentimento de humanidade para apontar onde foram parar as informações de que dispunham as três forças em 1993, conforme atestaram Exército, Marinha e Aeronáutica em relatórios militares referentes aos nossos desaparecidos, encaminhados à Câmara Federal e ao então Ministro da Justiça, Maurício Correa. ${ }^{382}$

Resta apenas uma conclusão para medidas como esta: houve um receio de que a participação desses familiares possibilitasse um revanchismo daquilo que havia sido acordado com a Lei da Anistia?

De acordo com o direito internacional, é obrigação do Estado investigar e punir os agentes responsáveis pelos casos graves de violações de Direitos Humanos. Em dezembro de 2010, a Corte Interamericana de Direitos Humanos da OEA condenou o Estado Brasileiro por se negar a esclarecer e responsabilizar seus agentes que participaram do desaparecimento de mais de 70 opositores políticos na repressão contra a Guerrilha do Araguaia. Além disso, estendeu esta sentença aos cerca de 500 mortos e desaparecidos políticos, afirmando que a interpretação oficial da Lei da Anistia não é problema para tais atos reparatórios (Comparato, 2010. S/N).

As medidas de reparação do governo vêm demonstrando cada vez mais a falta de prioridade no processo de julgamento dos crimes cometidos pelo Estado, por mais que determinadas medidas pareçam progressistas, elas não dão conta de fazer o enfrentamento com os agentes da repressão. A Lei no 10.559, de 2002, deu ao anistiado o direito à reparação econômica com base no tempo em que esteve afastado de

\footnotetext{
${ }^{382}$ Carta Aberta em resposta ao governo federal. Dossiê de mortos e desaparecidos políticos no Brasil. Disponível em < www.desaparecidospoliticos.org.br/pagina.php?id=259\&m=6 >, acesso em 30 de novembro de 2011.
} 
suas atividades, assim como a sua reintegração aos cargos, além de garantir o direito a conclusão de cursos.

Em consequência dessa lei, desde 2008, fora criada a Caravana da Anistia, com intuito de percorrer os estados brasileiros para julgar os processos de pessoas que foram presas e torturadas durante a ditadura. A manutenção do silêncio sobre os crimes da repressão tem sido práticas de governos que sucederam os militares. O descaso tem se dado não só com relação aos desaparecidos políticos como também aos processos de sigilo dos documentos do período.

A "Lei dos Arquivos" (Lei $n^{0} 8.159$ de 1991) tem como principal objetivo definir as regras de acesso aos arquivos públicos e privados, inclusive todos os que foram produzidos no período da ditadura civilmilitar. Por mais que ela permita 0 acesso aos documentos públicos ${ }^{383}$ para todos aqueles que envolver risco a segurança e a integridade do Estado, ela também prevê o limite ao acesso de 100 anos sem prorrogação (BRASIL, 1991).

As novas Leis que foram elaboradas demonstram cada vez mais as limitações estabelecidas no acesso aos documentos do período. Ao baixar o Decreto $n^{0} 4.553$, Fernando Henrique Cardoso determinou que o prazo para o acesso aos documentos sigilosos é de 50 anos podendo ser prorrogado em tempo indeterminado. Dois anos depois, Luis Inácio Lula da Silva modifica esse artigo estipulando o prazo de 30 anos, sendo prorrogado por mais uma vez.

Porém o governo Lula legitimou as perspectivas de ocultação da verdade da ala conservadora dos militares ao criar a Lei $n^{0} 11.111$ que retomava os prazos estabelecidos pela Lei $n^{0}$ 8.159. Definiu uma comissão de averiguação composta apenas por órgãos do Estado (Chefe da Casa Civil, Ministro da Justiça, Ministro da Defesa, Ministro das Relações Exteriores, Secretário dos Direitos Humanos) excluindo a possibilidade de participação de instituições e movimento sociais que lutam contra a violação dos direitos humanos e pelo direito à verdade.

\section{A COMISSÃO DA VERDADE NO BRASIL}

O Brasil é o país que mais está atrasado no processo de investigação e julgamento dos crimes do período da ditadura. Isso significa que a luta por justiça e reparação não deve se encerrar com as

\footnotetext{
${ }^{383} \mathrm{~A}$ Lei determina como prazo de sigilo o período de trinta anos, a contar da data de sua produção, podendo ser prorrogado por uma única vez pelo mesmo período. BRASIL. Lei $n^{\circ} 8.159$, de 8 de janeiro de 1991. Disponível em < http://www.planalto.gov.br/ccivil_03/leis/L8159.htm >, acesso em 02 de dezembro de 2011.
} 
reparações financeiras estipuladas pelos governos civis no pós-ditadura. Precisamos mobilizar a sociedade para garantir o direito à memória e à verdade e, com isso, estabelecer uma perspectiva de luta no tempo presente. A luta pelo direito à verdade se perpetua até os dias de hoje encabeçada principalmente por familiares de desaparecidos, perseguidos políticos e organizações em defesa dos direitos humanos.

Ainda no processo de abertura política, o Arcebispo de São Paulo, o Cardeal Paulo Evaristo Arns, dirigiu um processo de investigação sobre os crimes cometidos pelo regime autoritário. A Arquidiocese de São Paulo trabalhou durante 5 anos (Agosto de 1979 à março de 1985) em sigilo para obter os documentos oficiais, analisá-los, comprovar as informações e denunciar as atrocidades.

O resultado do trabalho se difundiu em 5000 páginas com o título "Brasil nunca mais", e sua síntese se transformou em um livro com o mesmo título que fora publicado em 1985. Este livro descreve as maneiras cruéis e degradantes das torturas ocorridas nos porões, além de apresentar dados históricos sobre as origens do regime autoritário, e 0 desenvolvimento do aparato repressivo que possibilitou 0 atropelo aos direitos humanos.

Essas investigações não possuíam relação com o Estado, e muito menos com o governo que dirigia a transição por meio da lógica do arbítrio. Porém a iniciativa foi um importante instrumento de denúncias de violações. Os familiares dos desaparecidos e as vítimas seguiram lutando por esclarecimento, verdade e punição dos responsáveis pelos crimes.

Recentemente fora apresentada uma nova proposta do Plano Nacional de Direitos Humanos PNDH 3. O intuito é criar orientações que debatam a fundo as violações de direitos humanos presentes na sociedade de hoje. $\mathrm{O}$ Eixo Orientador IV vem trazer a discussão sobre 0 direito à memória e à verdade, para isso surgiu a proposta de criação de uma Comissão da Verdade. Transformado em PL ñ 7.376/2010, e posteriormente na lei 12.518/2011, essa Comissão trouxe uma discussão sobre a necessidade de trazer à justiça os crimes cometidos pelos militares e seus financiadores. O Grupo "Tortura Nunca Mais" lançou uma nota analisando a aprovação da lei:

Se a proposta apresentada pelo governo federal já se caracterizava por sua timidez, as emendas apresentadas pelo DEM - e aceitas em um grande acordão pela Presidente da República piorou ainda mais o projeto. Antes, o texto do projeto estreitava a margem de atuação da Comissão, dando-Ihe poderes legais diminutos, fixando um pequeno número de integrantes, negando-Ihe orçamento próprio; desviando o foco de sua atuação ao fixar em 42 anos o período a ser investigado (de 1946 a 1988!), extrapolando assim em duas décadas a já extensa duração da Ditadura Militar. Além disso, impede que a Comissão investigue as responsabilidades pelas 
atrocidades cometidas e envie as devidas conclusões às autoridades competentes, para que estas promovam a justiça. ${ }^{384}$

A Comissão da Verdade é formada por apenas 7 membros escolhidos diretamente pela presidente Dilma, dando-Ihes poderes legais. São eles: Gilson Dipp, José Carlos Dias, José Paulo Cavalcanti Filho, Maria Rita Kehl, Paulo Sérgio Pinheiro, Rosa Cardoso e Pedro Dallari (atual coordenador da CNV). Claudio Fonteles integrou o colegiado entre maio de 2012 e junho de 2013. ${ }^{385}$

A comissão desvia 0 foco central, na medida em que amplia em 42 anos 0 período a ser investigado (1946 - 1988), reduzindo da história do Brasil os anos de ditadura civil-militar (1964 - 1985). Além disso, existe o fato de a mesma não ter o poder de responsabilizar e punir ninguém. Os próprios integrantes fazem questão de deixar claro que o objetivo é a reconstrução da memória sem nenhum tipo de revanchismo ou perseguição.

Em dezembro de 2009, foi apresentada uma nova proposta do Plano Nacional de Direitos Humanos - PNDH 3. Tal plano foi instituído pelo Decreto n. 7037 de 21 de dezembro de 2009, proposto por 31 ministérios, atualizando as versões anteriores e incorporando resoluções da Décima Primeira Conferência Nacional de Direitos Humanos. $O$ intuito é criar orientações que debatam a fundo as violações de direitos humanos presentes na sociedade de hoje. É importante detalhar o Eixo Orientador IV, em suas diretrizes 23, 24 e 25, que vem trazer a discussão sobre o direito à memória e à verdade.

$E$, no bojo de tais questões, foi votada em regime de urgência a Comissão da Verdade ${ }^{336}$. É evidente que essa proposta é bastante limitada e o Governo Dilma tem demonstrado uma incapacidade de fazer da Comissão da Verdade um instrumento de justiça.

Atravessados por todas as tensões e os acordos firmados entre os civis e militares durante 0 processo de transição, a Comissão Nacional da Verdade foi votada como "aquilo que é possível hoje". Em seu discurso na cerimônia de instalação da Comissão, a Presidente deixa claro que:

Ao instalar a Comissão da Verdade não nos move o revanchismo, o ódio ou 0 desejo de reescrever a história de uma forma diferente do que aconteceu, mas nos move a necessidade

384 Comissão da Verdade. Mais uma farsa, mais um engodo. Grupo Tortura Nunca Mais, Disponível em $<$ http://www.torturanuncamais-ri.org.br/Noticias.asp?Codnoticia=305 >, acesso em 30 de novembro de 2011.

385 Quem é quem. Comissão Nacional da Verdade. Acesso: http://www.cnv.gov.br/index.php/institucional-acessoinformacao/quem-e-quem em 10 de março de 2014.

${ }^{386}$ A comissão esteve inserida em uma nova proposta do Plano Nacional de Direitos Humanos - PNDH 3. O intuito é criar orientações que debatam a fundo as violações de direitos humanos presentes na sociedade de hoje. O Eixo Orientador IV vem trazer a discussão sobre 0 direito à memória e à verdade, para isso surgiu a proposta de criação de uma Comissão da Verdade. Transformado em PL no 7.376/2010, e posteriormente na Lei 12.518/2011. 
imperiosa de conhecê-la em sua plenitude, sem ocultamentos, sem camuflagens, sem vetos e sem proibições. O que fazemos aqui, neste momento, é a celebração da transparência da verdade de uma nação que vem trilhando seu caminho na democracia, mas que ainda tem encontro marcado consigo mesmo. Nesse sentido... E nesse sentido fundamental, essa é uma iniciativa do Estado brasileiro e não apenas uma ação de governo. ${ }^{387}$

O que ela chama de revanchismo, os movimento sociais denominam de justiça. Pois de que adianta a verdade se essa não servir de instrumento de luta contra a impunidade? É aí que habita uma das principais limitações da comissão: impedir que haja a investigação dos responsáveis pelas atrocidades cometidas e envie as devidas conclusões às autoridades competentes para que essas promovam a punição dos criminosos. Sem contar que a publicação de suas conclusões irá depender dos interesses da própria comissão.

\section{COMISSÕES DA VERDADE NO CHILE E NA ARGENTINA: APONTAMENTOS E LIMITES.}

As formações das comissões da verdade se pautaram por semelhanças no contexto histórico e político que foram influenciadas, tanto em sua natureza quanto no desenvolvimento de seus trabalhos pelo processo de transição. $\mathrm{Na}$ Argentina e no Chile, por exemplo, elas fizeram parte das primeiras medidas tomadas pelos governos civis que sucederam os militares. Ambas surgiram por um decreto presidencial e pelas demandas nacional e internacional das organizações que lutam por direitos humanos.

Tais semelhanças expressaram ações conjunturais dos próprios militares que, antes de deixar 0 Estado, buscaram neutralizar quaisquer possibilidades de julgamento aos atos criminosos cometidos por eles. Neste sentido foram criadas leis que buscavam apagar as atrocidades de suas ações com a justificativa de combate ao terrorismo.

Mesmo assim, os civis que sucederam os militares se comprometeram, enquanto plataforma política, a romper com as prerrogativas autoritárias dos militares e iniciar um processo de reconhecimento das atrocidades cometidas pelo Estado, no sentido de promover justiça e reparação.

$\mathrm{Na}$ Argentina, após as eleições diretas, Raúl Alfonsín da UCR se tornou o presidente. Imediatamente foi criada a Comisión Nacional Sobre La Desaparición de Personas - CONADEP. Formada por meio do Decreto no 187 de 15 de dezembro de 1983, composta por 12 membros nomeados pelo Presidente, 0 objetivo era investigar o paradeiro dos presos políticos e desaparecidos entre março de 1976 a dezembro

\footnotetext{
${ }^{387}$ Discurso da presidenta Dilma Rousseff na cerimônia de instalação da Comissão da Verdade - Brasília. Palácio do Planalto, 16 de maio de 2012. Acesso: <http://www2.planalto.gov.br/imprensa/discursos/discurso-da-presidenta-da-republica-dilmarousseff-na-cerimonia-de-instalacao-da-comissao-da-verdade-brasilia-df> em 10 de março de 2014.
} 
de 1983. Para isso a comissão deveria receber denúncias sobre esses atos com o intuito de elaborar um informe sobre o trabalho da comissão para ser entregue ao governo. 0 Art. $2^{\circ}$ do Decreto estabelece tais finalidades:

\begin{abstract}
Seran funciones especificas y taxativas de la Comision lassiguientes: a) recibir denuncias y pruebas sobre aquellos hechos y remitirlas inrnediatamente a la justicia si ellas estan reiacionadas con la presunta comision de delitos; b) averigurar el destino o paradero de las personas desaparecidas, como asi tambien toda otra circunstancia relacionada con su localizacion; c) determinar la ubicacion de ninos sustraidos a la tutela de sus padres o guardadores a raiz de acciones emprendidas con el motivo alegado de reprimir al terrorismo, y dar intervencion en su caso a los organismos y tribunales de proteccion de menores; d) denunciar a la justicia cualquier intento de ocultamiento, sus-traccion 0 destruccion de elementos probatorios relacionados con los hechos que se pretende esclarecer; e) emitir un informe final, con una explicacion detallada de los hechos investigados, a los ciento ochenta (180) dias a partir de su constitucion. ${ }^{388}$
\end{abstract}

Ao longo dos nove meses de atividades, foram realizadas coletivas de imprensa, entrevistas orais com os familiares das vítimas, mesas redondas. A comissão recebeu os familiares em sua sede para que denunciassem as violações de direitos humanos e identificassem centros clandestinos de torturas. Além disso, os membros poderiam requerer aos funcionários das forças armadas os informes, documentos, assim como 0 acesso aos lugares que a comissão achasse importante de ser investigado. ${ }^{389}$

Como fruto deste trabalho, em 20 de setembro de 1984, foi entregue ao presidente e à sociedade 0 informe completo denominado "Nunca más". Segundo o informe, aproximadamente 9.000 pessoas foram desaparecidas, segundo denúncias documentadas e comprovadas. O informe trouxe também elementos detalhados dos desaparecimentos, informações como a faixa etária das vítimas dos militares, o turno em que ocorriam os sequestros etc.

A CONADEP constatou também a existência de 340 centros clandestinos, onde ocorriam as torturas e os desaparecimentos, além de divulgar uma lista de 1351 agentes repressores, entre eles setores civis como bispos, médicos, juízes e jornalistas. A metodologia desenhada para o estabelecimento de uma verdade e o curto prazo para a investigação excluíram muitos casos pequenos de violações, pois a CONADEP centrou suas investigações nos casos de desaparecimento de pessoas.

A CONADEP criou um conjunto de recomendações aos três poderes do Estado. O objetivo era evitar que novas violações de Direitos Humanos ocorressem, assim como reparar e trazer justiça às vítimas da

\footnotetext{
${ }^{388}$ Decreto $n^{0}$ 187/83. Comisión Nacional sobre la Desaparición de las Personas. Del 15/12/1983, Disponível em: < http://www.derechos.org/ddhh/arg/ley/conadep.txt> Acesso em 17 de fevereiro de 2014.

389 CAPÍTULO IV. Forma e 0 funcionamento da CONADEP. Informe Nunca Más. Disponível em: $<$ http://www.derechoshumanos.net/lesahumanidad/informes/argentina/informe-de-la-CONADEP-Nunca-mas-Indice.htm\#C4> Acesso em 24 de Fevereiro de 2014.
} 
ditadura. Entre as propostas destacam-se: a continuidade de reparação por parte do poder judiciário; a reparação econômica às vítimas; distribuição de bolsas de estudo e trabalho aos familiares de desaparecidos; a criação de leis que condenassem os crimes de lesa humanidade e os desaparecimentos forçados de pessoas. Além disso, recomendou o ensino obrigatório de Direitos Humanos nas escolas estaduais e declarou apoio aos organismos ligados à área. Partes dessas recomendações ainda não foram colocadas em prática pelo Estado, porém os organismos internacionais têm cumprido um papel importante para pressionar o estado na realização e efetivação de tais recomendações.

Já no Chile, em abril de 1990, o Presidente eleito, Patrício Aylwin, criou a Comisión Nacional de Verdad e Reconciliación (CNVR). O objetivo do governo era abrir um processo de investigação dos crimes cometidos durante a ditadura, para com isso estabelecer uma reconciliação através de uma "verdade global". Ora, as pessoas que foram torturadas e perseguidas sofreram um grave processo de violação de direitos humanos e o fato da comissão não investigar esses casos se torna um aspecto insuficiente para aquilo que ela pretende ser.

Ao analisar o Decreto $n^{0} 355$ de 25 de abril de 1990390, percebe-se que diferentemente do que aconteceu na Argentina a comissão apresentou alguns elementos que a tornaram ainda mais parcial e limitada. Já em seu artigo primeiro, o decreto estabelece que:

Créase una Comisión Nacional de Verdad y Reconciliación que tendrá como objeto contribuir al esclarecimiento global de la verdad sobre las más graves violaciones a los derechos humanos cometidas en los últimos años, sea en el país o en el extranjero, si estas últimas tienen relación con el Estado de Chile o con la vida política nacional, com el fin de colaborar a la reconciliación de todos los chilenos y sin perjuicio de los procedimientos judiciales a que puedan dar lugar tales hechos. Para estos efectos se entenderá por graves violaciones las situaciones de detenidos desaparecidos, ejecutados y torturados con resultado de muerte, en que aparezca comprometida la responsabilidad moral del Estado por actos de sus agentes o de personas a su servicio, como asimismo los secuestros y los atentados contra la vida de personas cometidos por particulares bajo pretextos políticos. ${ }^{391}$

Podemos identificar vários problemas e contradições. O primeiro deles é sobre a redefinição de "violação dos Direitos humanos", ampliando não só a responsabilidade do Estado, como também as particularidades com pretextos políticos. Este foi um dos aspectos de maior crítica das organizações de direitos humanos, dos grupos de familiares e das próprias vítimas. Como é que se pode igualar a responsabilidade do Estado com a dos grupos de pessoas que atuaram contra a ditadura?

\footnotetext{
390 Decreto do poder executivo que estabelece a criação da CNVR. Disponível:< http://www.indh.cl/wpcontent/uploads/2010/10/ds355.pdf > Acesso em 10 de Abril de 2014.

${ }^{391}$ CHILE, Decreto n 355/90. Disponível: <http://www.indh.cl/wp-content/uploads/2010/10/ds355.pdf> Acesso em 10 de abril de 2014.
} 
Não era também objetivo investigar, declarar e identificar os culpados, e muito menos garantir 0 processo judicial. $O$ argumento para esta decisão foi o Artigo $n^{0} 2$ do decreto que dizia: em nenhum caso a comissão poderá assumir funções judiciais próprias dos tribunais de justiça e nem interferir nos processos pendentes. Não poderá pronunciar sobre as responsabilidades que poderia caber às pessoas individualmente pelos atos de tomada de conhecimento.

No capítulo 2, letra C (critérios) do Torno I do informe da CNVR, há uma explicação das razões da omissão dos nomes. Afirma-se que se fossem inclusos os nomes dos responsáveis, o poder executivo acusaria publicamente as violações e consequentemente estaria violando o ponto do decreto onde a comissão não teria o caráter judicial. Para o governo, isso seria uma violação dos princípios do estado de direito e de separação de poderes (INFORME DE LA COMISSIÓN NACIONAL DE LA VERDAD Y RECONCILIACIÓN, 1996, p.66). Apesar de reunir numerosos antecedentes que permitam individualizar os responsáveis, nada disso foi mencionado no informe, porque implicava em assumir funções judiciais e isso seria inconstitucional.

Ainda sobre o decreto de criação da comissão da verdade no Chile, percebe-se que não existiram atribuições para obrigar nenhuma pessoa ligada às forças armadas a comparecer. Estas, por sua vez, ficaram relutantes em entregar informações, já que também não era obrigatória a sua entrega. Quando surgia a necessidade de se obter informações e documentos, as forças armadas diziam que boa parte deles teriam sido queimados (CUERVAS; ROJAS; BAEZA, 2002, p. 49).

O presidente nomeou 8 membros ligados a pauta dos direitos humanos, e estes por sua vez teriam 0 prazo de 6 meses com a prorrogação de mais 3 meses para investigar os crimes cometidos de 11 de setembro de 1973 até março de 1990. Percebe-se que este prazo possibilitaria um trabalho pouco exaustivo, e as denúncias permaneceram sem a convicção de que se tratava de violação dos Direitos Humanos. (DECRETO No 355 1990, p.02).

Em 8 de fevereiro de 1991, os meios de comunicação transmitiam a entrega do informe da comissão presidida por Raúl Rettig. Um mês depois, o presidente Aylwin se dirigiu ao país para apresentar uma síntese do documento, suas reflexões sobre a verdade, a justiça e a reconciliação nacional, chamou a sociedade a assumir esta verdade com interesse e responsabilidade. Cada família recebeu um exemplar do informe e o restante foi publicado no diário estatal da nação (CUERVAS; ROJAS; BAEZA, 2002, p.71).

$O$ informe do CNVR divide-se em dois volumes e três tornos. Nele constatou-se que 3400 pessoas foram presas, desaparecidas e executadas como resultado de tortura. O informe apontou que houve uma 
política de extermínio sistemático contra os opositores políticos de esquerda, tendo como o principal órgão o DINA (Direción de Inteligencia Nacional) ${ }^{392}$.

Assim como na Argentina, a comissão apresentou algumas recomendações, dentre as quais a de obrigar o Estado a gerar políticas públicas que reparem as vítimas e tornem inviável a repetição das violações.

Mesmo com todas as críticas apresentadas pelas organizações ${ }^{393}$, foi reconhecido que o informe seria um passo importante para o processo de transição no Chile. A direita política foi ambígua em suas declarações públicas. Por um lado, aceitaram o informe e condenaram as violações relatadas, por outro, as justificativas se pautaram pelo excesso inevitável no marco de enfrentamento. As forças armadas desqualificaram o informe, em vez de reconhecer as atrocidades cometidas, justificaram os atos como sendo uma ação patriótica (CUERVAS; ROJAS; BAEZA, 2002, p. 75).

Tanto no Chile quanto na Argentina, o cumprimento das recomendações tem dependido da vontade política dos governos e do poder legislativo. Nesses países as recomendações contribuíram para que houvesse reparação às vítimas, além de iniciar um processo de reconciliação e prevenir futuras violações dos direitos humanos. As Comissões da Verdade elaboraram recomendações dirigidas ao poder judiciário no sentido de promover reformas e modificações com o intuito de avançar no processo de reconciliação do Estado com as vítimas do regime.

\section{CONSIDERAÇÕES FINAIS}

A ditadura civil-militar deixou marcas profundas na sociedade brasileira, e a transição pactuada tentou impor uma conciliação que busca apagar da memória coletiva todas as atrocidades cometidas pelos governos autoritários. A luta travada em torno das vítimas e das obrigações do Estado está distante de se encerrar. Isso porque as políticas de reparação não são condizentes com os reais interesses de familiares que lutam por justiça. Infelizmente, a ideia de conciliação imposta pela Lei da Anistia fez com que a luta pela reparação e justiça não conseguisse envolver de maneira efetiva a sociedade civil como um todo.

\footnotetext{
392 No torno II, o informe aponta as origens e o papel deste órgão. O informe constatou que o DINA foi criado com a função de reprimir os chamados "inimigos políticos", com a justificativa de recolher informações para garantir a segurança nacional e desenvolver o país. Informe CNVR, Torno II, p, 722.

393 As críticas se apresentam nos seguintes aspectos: o informe se resumiria apenas aos casos de investigação com resultado de morte, excluía as práticas gerais de torturas, o exílio as prisões ilegais, as violações dos devidos processos legais. - o fato de incluir as vítimas nas investigações de violações dos direitos humanos - a não indicação de responsáveis, ocultando a identidade dos autores cúmplices e encarregados.
} 
Nesse sentido, se torna necessário o posicionamento favorável à Comissão Nacional da Memória, Verdade e Justiça onde todos os arquivos da ditadura sejam abertos e públicos, e as investigações responsabilizem os agentes do Estado autoritário que cometeram crimes contra a humanidade. A reconstrução da memória deve trazer a tona uma verdade que promova a justiça e não o esquecimento e 0 apaziguamento em nome da segurança nacional.

Para isso é extremamente importante que haja a imediata revisão da lei da anistia e o rompimento dos acordos estabelecidos ao longo da transição. Só assim o Estado brasileiro, além de reconhecer que houve atrocidades, vai avançar no tocante à reparação às vítimas - julgando os culpados por cometerem violações de direitos humanos e trazendo a tona a verdade sobre tais atos.

\section{REFERÊNCIAS BIBLIOGRÁFICAS.}

ARANTES, Paulo Eduardo. 1964, o ano que não terminou. TELES, Edson. In: SAFATLE, Vladmir (Org.). 0 que resta da ditadura. São Paulo: Ed. Boitempo. 2010 - (Estado de Sítio).

BENJAMIN, Walter. Sobre o Conceito de história. In: Magia e técnica, arte e política.(Obras escolhidas, vol. 1). Tradução de Paulo Sérgio Rouanet - 7 ed. São Paulo: Brasiliense, 1994 (pp.222/232).

COMPARATO, Fábio Konder. O risco de o Brasil tornar-se um estado fora da lei no Plano Internacional: Os efeitos da sentença da Corte Interamericana de Direitos Humanos no Caso Gomes Lund e Outros v. Brasil. Brasília, 1 de Agosto de 2013. Disponível em < http://conflitos-juridicos.blogspot.com.br/2013/08/0risco-de-o-brasil-tornar-se-um-estado.html>. Acesso em 05 de Agosto de 2013.

Corte interamericana de direitos humanos, caso Gomes Lund vs. Brasil. Estudo elaborado por alunos da Faculdade de Direito da Universidade de São Paulo. Disponível em < http://www.direito.usp.br/extensao-/Arquivos/amicus dh_novo_estudo.pdf $>$ Acesso em 26 de Agosto de 2013.

Comissão da Verdade: mais uma farsa, mais um engodo. Grupo Tortura Nunca Mais Disponível em $<$ http://www.torturanuncamais-rj.org.br/Noticias.asp?Codnoticia=305>. Acesso em 28 de Novembro de 2011.

CUEVAS, Victor Espinoza. ROJAS, María Luisa Ortiz. BAEZA, Paz Rojas. Comisiones de Verdad; Um Camino incierto? Estudio comapativo de comissiones de la verdade en Argentina, Chile, El Salvador, Guatemala y sudáfrica desde las victimas y las organizaciones de derechos humanos. CODEPU - Chile e APT - Suiza, $2002 . \quad$ Disponível em <http://www.dhnet.org.br/verdade/mundo/textos/cuevas_cv_camino_cierto_paises.pdf> Acesso em: 26 de agosto de 2013.

DREIFUSS, René Armand. 1964, a conquista do Estado. Petrópolis: Vozes, 1981.

FERNANDES, Florestan. A ditadura em questão. 2 ed. São Paulo: T. A. Queiroz, 1982.

GORENDER, Jacob. Combate nas trevas. A esquerda brasileira: das ilusões perdidas à luta armada. 1987, editora ática.

LE GOFF, Jacques. História e Memória. Campinas/ SP: UNICAMP, 2003.

MACIEL, David. A aliança Democrática e a transição politica no Brasil. PINHEIRO, Milton (Org). Ditadura: 0 que resta da transição. São Paulo: Ed. Boitempo, 2014 - (Estado de Sítio) 
. Crise do desenvolvimentismo e transição política no Brasil. SILVA, Carla Luciana; CALIL, Gilberto Grassi; SILVA, Marcio Antônio Bath da. (Org's). Ditaduras e democracias: Estudos sobre poder, hegemonia e regimes políticos no Brasil (1945 - 2014). Porto Alegre: FCM Editora, 2014.

MORAES, João Quartim de. A natureza de classe do Estado brasileiro. SILVA, Carla Luciana; CALIL, Gilberto Grassi; SILVA, Marcio Antônio Bath da. (Org's). Ditaduras e democracias: Estudos sobre poder, hegemonia e regimes políticos no Brasil (1945 - 2014). Porto Alegre: FCM Editora, 2014.

NERY, Vanderley Elias. Diretas já: mobilizações de massas com direção burguesa. PINHEIRO, Milton (Org). Ditadura: o que resta da transição. São Paulo: Ed. Boitempo, 2014 - (Estado de Sítio)

SAFATLE, Vladimir. Do uso da violência contra o estado ilegal. In: TELES, Edson. SAFATLE, Vladmir (Org.). O que resta da ditadura. - São Paulo: Ed. Boitempo. 2010 - (Estado de Sítio).

SILVA, Francisco Carlos Teixeira da. "Crise da ditadura militar e o processo de abertura política no Brasil". In: FERREIRA, Jorge \& DELGADO, Lucilia de Almeida Neves (Orgs). O Brasil Republicano: O tempo da ditadura. RJ Civilização Brasileira, 2007.

TELES, Janaína de Almeida. Os familiares de mortos e desaparecidos políticos e a luta por "verdade e justiça" no Brasil. In: TELES Edson. SAFATLE, Vladmir (Org.). O que resta da ditadura. São Paulo: Ed. Boitempo. 2010 - (Estado de Sítio)

\section{FONTES}

MENSAGEM N 059, DE 1979. Anistia Vol I. Congresso Nacional, Brasília. 1982, p. 21-25

BRASIL. Lei $n^{0}$ 6.683, de 28 de agosto de 1979. Disponível em < http://www.planalto.gov.br/ccivil_03/leis//6683.htm >. Acesso em 08 de dezembro de 2011.

BRASIL. Decreto $n^{0} 4.553$, de 27 de dezembro de 2002 . Disponível em <http://www.planalto.gov.br/ccivil 03/decreto/2002/D4553.htm>. Acesso em 08 de dezembro de 2011.

BRASIL. Decreto $n^{0} 5 . \overline{3} 01$, de 9 de dezembro de 2004 . Disponível em <http://www.planalto.gov.br/ccivil_03/_Ato2004-2006/2004/Decreto/D5301.htm>. Acesso em 08 de dezembro de 2011.

BRASIL. Lei $n^{0} 8.159$, de 8 de janeiro de 1991. Disponível em < http://www.planalto.gov.br/ccivil_03/leis/L8159.htm>. Acesso em 08 de dezembro de 2011.

BRASIL. Lei $n^{0} 11.1 \overline{1}$, de 5 de maio de 2005. Disponível em < http://www.planalto.gov.br/ccivil_03/_Ato2004-2006/2005/Lei/L11111.htm>. Acesso em 08 de dezembro de 2011.

BRASIL. Lei $n^{0}$ 12.528, de 18 de novembro de 2011. Disponível em < http://www.planalto.gov.br/ccivil_03/_Ato2011-2014/2011/Lei/L12528.htm>. Acesso em 26 de agosto de 2013.

CHILE. Decreto no 355/90. Disponível em : <http://www.indh.cl/wp-content/uploads/2010/10/ds355.pdf> Acesso em 10 de abril de 2014.

COMISIÓN NACIONAL SOBRE LA DESAPARICIÓN DE PERSONAS (CONADEP) Informe nunca más. Argentina. Setembro de 1984. Disponível em < http://www.derechoshumanos.net/lesahumanidad/informes/argentina/informe-de-la-CONADEP-Nunca-mas.htm > Acesso em 16 de Abril de 2014.

COMISIÓN NACIONAL DE VERDAD Y RECONCILIACIÓN (CNVR). Informe de la Comisión Nacional de Verdad $y$ Reconciliación. Chile, 1991. Disponível em: < http://www.derechoshumanos.net/lesahumanidad/informes/informe-rettig.htm > Acesso em 16 de Abril de 2014. 
Comissão do Senado aprova revisão da Lei da Anistia. Folha de São Paulo. Disponível em: < http://www1.folha.uol.com.br/poder/2014/04/1438111-comissao-do-senado-aprova-revisao-da-lei-daanistia.shtml > Acesso em: 17 de Abril de 2014.

Limites a Cháves. Folha de São Paulo: <http://www1.folha.u-ol.com.br/fsp/opiniao/fz1702200901.htm > Acesso em: 17 de Abril de 2014.

Maior parte da população quer anular a Lei da Anistia, aponta Datafolha. Folha de São Paulo. Disponível em : < http://www1.folha.uol.com.br/poder/2014/03/1433374-maior-parte-da-populacao-quer-anular-lei-daanistia-aponta-datafolha.shtml > Acesso em: 17 de abril de 2014.

Manifestações pró-golpe levam a fim de sessão da Câmara sobre ditadura. Rede Brasil Atual. Disponível em: < http://www.redebrasilatual.com.br/cid-adania/2014/04/manifestantes-pro-golpetumultuam-sessao-da-camara-sobre-ditadura-6533.html > Acesso em: 17 de Abril de 2014.

NAÇÕES UNIDAS. "Relatório do Secretário-Geral. O Estado de direito e a justiça de transição em sociedades em conflito e pós-conflito", de 23 de agosto de 2004. In: Revista Anistia Política e Justiça de Transição. Brasilia: Ministério da Justiça, 2009, no 1 (Jan/jun. 2009).

SECRETARIA DE DIREITOS HUMANOS DA PRESIDÊNCIA DA REPÚBLICA. Plano Nacional de Direitos Humanos 3. Disponível em < http://portal.mj.gov.br/sedh/pndh3/pndh3.pdf>. Acesso em 08 de dezembro de 2011.

ARGUIÇÃO DE DESCUMPRIMENTO DE PRECEITO FUNDAMENTAL n 153. Supremo Tribunal Federal. Distrito Federal. 29/04/2010

O Projeto de Anistia. Jornal da Cidade. Aracaju (SE) 23/03/1979. p, 02. Ano VIII. № 1952.

Rejeição da Emenda Dante de Oliveira pela Câmara completa 30 anos. Correio Brasiliense. Acesso: $<$ http://www.correiobraziliense.com.br/app/noticia/politica-/2014/04/25/interna_politica,424651/rejeicao-daemenda-dante-de-oliveira-pela-camara-completa-30-anos.shtml > em 14 de Setembro de 2014. 